\title{
Do Rates of Mental Health Symptoms in Currently Competing Elite Athletes in Paralympic Sports Differ from Non-Para- Athletes?
}

Lisa S. Olive ${ }^{1,2,3^{*}}$ (D) Simon Rice ${ }^{1,4}$, Matt Butterworth ${ }^{5}$, Matti Clements ${ }^{5}$ and Rosemary Purcell ${ }^{1,4}$

\begin{abstract}
Background: This study addresses the lack of comparative data on the mental health of athletes in Paralympic sports ('para-athletes') and non-para athletes by examining the prevalence and correlates of mental health symptoms in a national sample of elite athletes representative of the population from which it was drawn on age and para-status.

Methods: A cross-sectional, anonymous, online-survey was provided to all categorised (e.g. highest level) athletes, aged 17 years and older, registered with the Australian Institute of Sport $(n=1566)$. Measures included psychological distress, mental health caseness, risky alcohol consumption, body weight and shape dissatisfaction, self-esteem, life satisfaction, and problem gambling. Correlates of outcomes included individual (e.g. demographic and psychosocial) and sport-related variables.

Results: The participation rate was 51.7\% ( $n=810)$, with valid data available from 749 athletes. No significant differences were observed between athletes from para- and non-para-sports on most mental health symptoms, with the exception of alcohol consumption $(p<.001)$ and self-esteem $(p=.007)$, both lower in athletes from parasports. A trend for an interaction was found for anxiety and insomnia $(p=.018)$, whereby the difference between athletes from para- and non-para-sports was qualified by gender.

Conclusions: In a large sample of elite athletes, mental health and wellbeing symptoms are comparable between athletes from para- and non-para-sports, with the exception of para-athletes reporting lower alcohol consumption but also lower self-esteem. While overall mental health and wellbeing symptom profiles are largely similar, attention to areas of differences will help to better address the unmet and distinct mental health needs of athletes from para-sports.
\end{abstract}

Keywords: Mental health, Elite athlete, Paralympic sports, Depression, Anxiety, Body dissatisfaction, Alcohol use, Elite sport, Athlete

\footnotetext{
* Correspondence: lisa.olive@deakin.edu.au

'Orygen, 35 Poplar Road, Parkville, Melbourne, Victoria 3052, Australia

${ }^{2}$ Centre for Social and Early Emotional Development, School of Psychology,

Deakin University, Geelong, Australia

Full list of author information is available at the end of the article
}

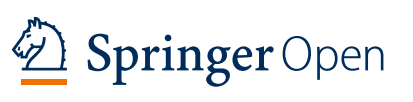

(c) The Author(s). 2021 Open Access This article is licensed under a Creative Commons Attribution 4.0 International License, which permits use, sharing, adaptation, distribution and reproduction in any medium or format, as long as you give appropriate credit to the original author(s) and the source, provide a link to the Creative Commons licence, and indicate if changes were made. The images or other third party material in this article are included in the article's Creative Commons licence, unless indicated otherwise in a credit line to the material. If material is not included in the article's Creative Commons licence and your intended use is not permitted by statutory regulation or exceeds the permitted use, you will need to obtain permission directly from the copyright holder. To view a copy of this licence, visit http://creativecommons.org/licenses/by/4.0/. 


\section{Key Points}

- Minimal differences in mental health and wellbeing symptoms were observed between a nationally representative sample of elite athletes from paraand non-para-sports.

- Of these minimal differences, athletes from parasports reported lower alcohol consumption but also lower self-esteem compared to athletes from nonpara-sports.

- The findings reported here highlight a similar need for mental health supports across athlete populations.

\section{Introduction}

There is increasing recognition of the mental health challenges and needs of elite and professional sportspeople [1]. However, there is little empirical evidence regarding the rates of mental health symptoms among elite athletes in Paralympic sports (hereon termed 'paraathletes') and a lack of comparative data with athletes from non-para-sports. To date, meta-analyses that estimate the prevalence of mental health symptoms in elite athletes, ranging from $19 \%$ for general psychological distress and/or alcohol misuse, through to 34\% for anxiety/ depression [2, 3], have mostly involved athletes from non-para-sports (e.g. predominantly male, professional team sports).

The existing body of knowledge regarding mental health in elite athletes applies to athletes from parasports; however, para-athletes are likely to experience a range of additional impairment-specific stressors that have the potential to compromise their mental health, such as discrimination [4], a lack of sufficient, adaptive sport facilities, logistical challenges in travel to competition sites and the cost of impairment-specific equipment [5]. Conversely, the Paralympic Movement and the status of the Paralympics has potentially facilitated the development of a range of protective factors for athletes relating to their involvement in elite sport and their identity as an elite athlete, which in turn may positively affect mental health [6, 7]. Understanding mental health symptoms, as well as mental wellbeing, in para-athletes is necessary to inform appropriate response frameworks and interventions.

In a systematic review (12 included studies) comparing general well-being in Olympic and Paralympic athletes [8], two studies reported significant differences in favour of Olympic athletes for life satisfaction, mooddisturbance, fatigue and depression $[9,10]$. A more recent narrative review that focused specifically on Paralympic athletes concluded that, given the paucity of published data much of which has been qualitative by design, relied on small sample sizes and often non- standardised measures of psychopathology, the only definitive course is for more focused research on the mental health of those who participate in elite competitive para-sports, including comparisons with elite athletes from non-para-sports [11].

To address this gap, we compared the prevalence and correlates of mental health symptoms in elite paraathletes with the rates among athletes from non-parasports in a national sample of athletes representative of the population from which it was drawn on age and para-status (the Australian Institute of Sport [AIS] high performance sporting system). As the rates of mental health symptoms in the general (e.g. non-athletic) population are reported to be higher among people with disabilities than in non-disabled individuals, particularly for depression [12], we hypothesised that para-athletes would report higher rates of mental health symptoms compared to athletes from non-para-sports.

\section{Methods \\ Participants}

All elite para- and non-para-athletes aged 17 years and over, who were supported by the AIS via being contracted with a national sporting organisation (NSO) were invited to participate in an anonymous, online survey regarding their mental health and wellbeing (see [13] for a detailed study overview). AIS supported athletes can receive access to a range of resources, which include but are not limited to monetary support in the form of a grant, access to training/high performance resources (technology, equipment and personnel) and access to mental health and wellbeing support. There were no exclusion criteria other than age. Athletes completed the survey between July and September 2018. All participants were provided with information about the purpose of the survey prior to commencing and informed consent was obtained from athletes by them choosing to commence the survey, which was explained in the information provided to participants. The University of Melbourne Human Ethics Research Committee approved the study (\#1442705).

\section{Survey Items}

The survey consisted of the following sections and scales (see [13], for a comprehensive overview of the survey items).

\section{Background Information/Demographics}

In addition to basic demographic characteristics, athletes were asked whether or not they had competed in the 2018 Winter Olympics and Paralympics, or the 2018 Commonwealth Games (which included para-sports); their sport type (individual or team-based); the number of years contracted as an NSO athlete; whether they 
were currently injured or in adapted training programme due to injury; the frequency of sport-related travel over the past year; the experience of missing significant life events due to travel for sport; and whether they had 'ever been treated for a psychological issue or mental health problem (e.g. anxiety, depression)'.

\section{Symptom Outcome Measures}

Outcome measures were included in the following order, and where measured over the 4 weeks prior to the survey unless otherwise indicated. Mental health symptoms and 'caseness' were assessed using the 28-item General Health Questionnaire (GHQ-28) [14], which yields a total score and scaled scores for (i) somatic complaints, (ii) anxiety and insomnia, (iii) social dysfunction, and (iv) severe depression (including suicidal ideation). 'Probable caseness', defined as symptoms that adversely affect quality of life and are of a level frequently found among individuals seeking help from health professionals [15], can also be calculated from the GHQ-28. General Psychological Distress was measured using the Kessler 10 (K-10), a 10-item screening tool assessing psychological distress, including nervousness, fatigue, hopelessness, and depression [16]. The $\mathrm{K}-10$ has been widely validated in a range of populations [17-19] and demonstrated good reliability in the current sample of elite athletes $(\alpha=0.89)$. Self-esteem was measured using the validated 10-item Rosenberg Self Esteem Scale [20], with responses provided on 4-point Likert scale $(1=$ strongly disagree to 4 = strongly agree), whereby higher scores indicate higher self-esteem. This scale was found to be reliable in the current sample $(\alpha=0.87)$. Mental wellbeing was measured using the Warwick-Edinburgh Mental Wellbeing Scale (WEMWBS) [21], a 14-item scale assessing positive aspects of mental health as a single factor, such as feeling useful, relaxed, and optimistic [21, 22]. Responses are measured on a 5-point Likert scale $(1=$ none of the time to $5=$ all of the time), with higher scores indicating greater mental wellbeing. The WEMWBS showed good reliability in the current sample $(\alpha=0.93)$. Gambling behaviour over the past 12 months was measured using the 3-item Problem Gambling Severity Index (PGSI) [23]. Responses are provided on a 5-point Likert scale (ranging from 'never' to 'always'), with higher score indicating more problematic gambling behaviour. The PGSI showed good reliability in the current sample ( $\alpha=$ 0.94). Maladaptive response to psychological distress was measured using two subscales from the Male Depression Risk Scale (MDRS) [24], namely the anger and aggression (4 items) and risk-taking behaviour (3 items) subscales. Participants rate items relative to the preceding month, where $0=$ not at all to $7=$ almost always, with higher scores indicating greater risk. Both subscales were shown to be reliable in the current sample (anger and aggression $\alpha=0.90$; risk-taking behaviour $\alpha=0.80$ ). Body weight and shape dissatisfaction were assessed using the weight (5 items) and shape (8 items) subscales from the Eating Disorders Examination Questionnaire (EDEQ) [25]. Participants rate the severity of the psychopathology of eating disorders on a 7-point Likert scale, ranging from $0=a b$ sence of the feature to $6=$ feature present to an extreme degree, with higher scores indicating greater severity. $\mathrm{Al}$ cohol use in the past 12 months was measured by the Alcohol Use Disorders Test (AUDIT) [26], which yields a total score derived from scaled scores for (i) alcohol consumption, (ii) alcohol dependence, and (iii) alcohol-related problems, whereby higher scores indicate higher risk of an alcohol use disorder. The AUDIT total scale was found to have acceptable reliability in the current scale $(\alpha=0.69)$. Satisfaction with life (no time limit) was assessed using the 5-item Satisfaction with Life Scale [27]. Each item is assessed on a 7-point Likert scale ranging from $1=$ strongly disagree to 7 = strongly agree, with higher scores indicating higher life satisfaction, and was shown to be reliable in the current sample $(\alpha=0.90)$. Quality of life was assessed using a single item that rated quality of life on a 5 -point scale, ranging from 'very poor' to 'very good'.

\section{Psychosocial Correlates}

Adverse life events were assessed in the 12 months prior to the survey and lifetime, given the relationship between such events and psychopathology [28]. Thirteen items were included, such as death or serious illness of a loved one, relationship breakdown, and discrimination.

Social support was assessed using three questions [29] that examined the perceived availability and adequacy of social support, and sources of support, and social isolation was measured using three items that asked participants to rate the frequency with which they felt they lacked companionship, felt left out, and felt isolated from others. Help seeking for a personal or emotional problem was assessed using the 10-item General Help Seeking Questionnaire [30], where participants rate on a 7 -point Likert scale $(1=$ extremely unlikely to $7=\mathrm{ex}$ tremely likely) how likely it is that they would seek help. Coping style was assessed using the Billings and Moos Coping Scale [31], which yields scores on activecognitive (6 items), active-behavioural (6 items) and avoidance coping (5 items). Participants endorsed whether or not they utilised each coping strategy, using a yes/no response format, with higher scores indicating greater use of that style of coping.

\section{Patient and Public Involvement}

The survey was developed in consultation with the AIS' Athlete Wellbeing and Engagement team, who consulted with former and current athletes in the study design. 


\section{Data Analyses}

The binary GHQ-28 'probable caseness' outcome variable was analysed using logistic regression (categorical scoring involves applying weights to the four response alternatives (0-0-1-1) to produce a scoring range of 0 28. A cut-off of 5 was applied [15] in which participants scoring a total of five or more are considered a probable case). Other categorical outcomes variables, including the AUDIT Hazardous item (categorical scoring was based on AUDIT risk level classification where $0=$ low risk and 1 = hazardous risk or higher) and EDEQ derived body weight and shape dissatisfaction subscales $(0$ = no shape or weight dissatisfaction, 1 = endorsed 1 item, 2 = endorsed both items), were also analysed using logistic regression. For all other continuous variables, a two-way analysis of variance was used to determine differences between athletes from para-sports and nonpara-sports, males and females and their interaction (para-status $\mathrm{x}$ gender), with adjustment made for age. Given the number of analyses performed on the same dataset, outcomes were evaluated as statistically significant at $p \leq .01$ to reduce the chance of type I error, with Cohen's $d$ reported as a measure of effect size. All analyses were conducted using SPSS Version 25.

\section{Results}

\section{Participant Characteristics}

A total of 1566 athletes, of whom 16.0\% were paraathletes, were registered with the AIS and aged 17 years or older at the time of the survey and therefore eligible to participate $(52.5 \%$ male; $47.5 \%$ female; overall mean age $=24.5$ years $)$. Of these, 810 consented to participate (51.7\% response rate) and full data were available for analysis for 749 participants. The participating athletes were representative of the eligible population in relation to para-status (14.7\%) and mean age (24.6 years); however, a higher proportion of female athletes completed the survey (54.1\%).

The 110 participants from para-sports represented $44 \%$ of currently engaged AIS para-athletes. The majority were male with a mean age of $30.71(\mathrm{SD}=10.67)$, and Australian-born (91.8\%). At the time of the survey, most athletes from para-sports $(74.7 \%)$ reported being engaged in employment in addition to their role as elite athlete (comprising 59.2\% in paid employment, and $15.5 \%$ in unpaid voluntary work) and $32 \%$ were studying. Almost half of the participants were single or never married $(49.5 \%)$ and $37 \%$ had completed their highest level of secondary education. The demographic and sportsrelated characteristics of the para-athletes compared to non-para-athletes are summarised in Table 1.

Group differences were observed in relation to age $(t(734)-6.6, p<.001, d=0.9$; higher in para-athletes $)$, relationship status $\left(\chi^{2}=8.3, p<.001\right)$, highest level of education $\left(\chi^{2}=14.1, p<.01\right)$, length of time as an NSO categorised athlete $\left(\chi^{2}=16.6, p<.01\right)$, work outside of sport $\left(\chi^{2}=14.8, p<.01\right)$, current living arrangements $\left(\chi^{2}\right.$ $=25.2, p<.001)$, type of sport $\left(\chi^{2}=10.5, p<.001\right)$ and travel due to sport in the 12 months prior to the survey $\left(\chi^{2}=22.0, p<.001\right)$.

Para-athletes reported experiencing a significantly greater number of adverse life events over their lifetime $($ mean $=3.9[\mathrm{SD}=2.2]$ vs $2.8[1.8], t(598)=-4.1, p<$ $.001, d=0.5$ ), in particular being more likely than nonpara-athletes to report a personal injury or illness $(57.8 \%$ vs $28.8 \% ; p<.001)$, discrimination $(33.9 \%$ vs $9.4 \%$; $p<$ $.001)$, feeling undervalued $(41.3 \%$ vs $26.2 \% ; p<.001)$ and bereavement $(53.2 \%$ vs $30.9 \%$; $p<.01)$. However, there were no group differences in relation to the total number of adverse events reported in the year prior to the survey. The availability of social support also did not differ significantly between groups, nor did the perceived adequacy of social support or the degree of social isolation (items related to lack of companionship, feeling left out, and isolated).

\section{Comparison of Elite Para- and Non-para-athletes' Mental Health and Wellbeing Symptoms}

Scores on the outcome measures for athletes from parasports and non-para-sports are presented in Table 2. In unadjusted models, there were no significant group differences on any measure other than total score on the AUDIT, which was lower in para-athletes $(F(1,641)=$ 11.34, $p=.001$ ). Adjusted models (adjusting for age and gender) revealed similar results, whereby athletes from para-sports reported significantly lower total scores on the AUDIT $(F(1,625)=25.21, p<.001)$, although this effect was small $(d=0.3)$. Post hoc analyses were conducted at both the subscale level of the AUDIT (e.g. consumption score, dependence score and alcoholrelated problems score) and at the individual item level, adjusted for age and gender. At the subscale level, significant differences were observed between para- and non-para-athletes on the consumption score $(F(1,496)=$ 25.29, $p<.001, d=0.2$ ), with para-athletes reporting lower levels of alcohol consumption. Further investigation at the item level indicated that non-para-athletes reported consuming both a significantly greater number of standard drinks on a typical day when drinking (item 2; $F(1,497)=8.34, p=.004, d=0.5)$ and would more frequently consume six or more standard drinks on one occasion (item $3 ; F(1,497)=27.23, p<.001, d=0.5$ ). No differences were observed between athlete groups for the dependence score or alcohol-related problems score of the AUDIT (both $p>.01$ ).

Also in adjusted models, athletes from para-sports reported lower scores on the measure of self-esteem compared to non-para-athletes $(F(1,683)=7.22, p=.007 ; d$ 
Table 1 Demographic and sports-related characteristics of the para-athletes compared to non-para-athletes

\begin{tabular}{|c|c|c|c|c|c|}
\hline Demographic characteristics & $\begin{array}{l}\text { Para- } \\
\text { athletes } \\
\%(n)\end{array}$ & $\begin{array}{l}\text { Non-para- } \\
\text { athletes } \\
\%(n)\end{array}$ & Sport-related characteristics & $\begin{array}{l}\text { Para- } \\
\text { athletes } \\
\%(n)\end{array}$ & $\begin{array}{l}\text { Non-para- } \\
\text { athletes } \\
\%(n)\end{array}$ \\
\hline Gender (\% female) & $43.0(46)$ & $57.1(359)$ & $\begin{array}{l}\text { Individual sport** } \\
\text { Team-based sport }\end{array}$ & $\begin{array}{l}75.1(82) \\
24.8(27)\end{array}$ & $\begin{array}{l}58.8(371) \\
41.2(260)\end{array}$ \\
\hline Mean age $(S D)^{* *}$ & $\begin{array}{l}30.7 \\
(10.6)\end{array}$ & $23.4(4.7)$ & Recent competition & $24.5(27)$ & $20.6(131)$ \\
\hline Relationship status** & & & $\begin{array}{l}\text { Main activity related to sport in the } \\
\text { past month }\end{array}$ & & \\
\hline Single/never married & $49.5(54)$ & $55.0(350)$ & Actively engaged in sport & $49.1(54)$ & $57.6(367)$ \\
\hline Partnered & $29.4(32)$ & $36.8(234)$ & Training (in-season) & $18.2(20)$ & $19.0(121)$ \\
\hline Married & $18.3(20)$ & $7.5(48)$ & Training (off-season) & $20.0(22)$ & $12.6(80)$ \\
\hline \multirow[t]{2}{*}{ Separated/divorced } & $2.8(-)$ & $0.6(-)$ & Recovering from injury & $9.1(10)$ & $8.2(52)$ \\
\hline & & & Other & $3.6(-)$ & $2.7(17)$ \\
\hline $\begin{array}{l}\text { Sexual orientation } \\
\quad \text { Heterosexual } \\
\text { Bisexual } \\
\text { Same sex attracted } \\
\text { Other^} \wedge\end{array}$ & $\begin{array}{l}88.2(97) \\
3.6(-) \\
2.7(-) \\
5.5(6)\end{array}$ & $\begin{array}{l}93.2(593) \\
2.8(18) \\
1.7(11) \\
2.2(14)\end{array}$ & $\begin{array}{l}\text { Currently injured } \\
\text { Currently in an adapted training } \\
\text { programme due to injury }\end{array}$ & $\begin{array}{l}10.1(11) \\
12.7(14)\end{array}$ & $\begin{array}{l}12.9(82) \\
15.9(101)\end{array}$ \\
\hline Currently studying & $68.2(75)$ & $77.7(261)$ & Ever treated for a concussion & $13.6(15)$ & $15.9(101)$ \\
\hline $\begin{array}{l}\text { Highest level of education* } \\
\text { Completed }<\text { year } 12 \\
\text { Completed year } 12 \\
\text { University degree } \\
\text { Vocational qualification }\end{array}$ & $\begin{array}{l}14.7(16) \\
37.6(41) \\
29.4(32) \\
18.3(20)\end{array}$ & $\begin{array}{l}14.8(94) \\
54.2(345) \\
21.4(136) \\
9.6(61)\end{array}$ & $\begin{array}{l}\text { Length of time as an NSO categorised } \\
\text { athlete** } \\
\text { Less than } 12 \text { months } \\
1-3 \text { years } \\
4-7 \text { years } \\
8 \text { or more years } \\
\text { Do not know }\end{array}$ & $\begin{array}{l}10.1(11) \\
32.1(35) \\
26.6(29) \\
22.2(24) \\
9.2(10)\end{array}$ & $\begin{array}{l}16.0(102) \\
37.3(237) \\
19.5(124) \\
11.2(71) \\
13.7(102)\end{array}$ \\
\hline $\begin{array}{l}\text { Paid work in the past month* } \\
\text { None } \\
\text { Paid_casual } \\
\text { Paid_part time } \\
\text { Paid_full time } \\
\text { Voluntary (unpaid) }\end{array}$ & $\begin{array}{l}25.5(28) \\
25.5(28) \\
16.4(18) \\
17.3(19) \\
15.5(17)\end{array}$ & $\begin{array}{l}35.1(223) \\
30.2(192) \\
15.4(98) \\
13.1(83) \\
6.3(40)\end{array}$ & $\begin{array}{l}\text { Travel away due to sport }{ }^{* *} \\
\text { Less than } 1 \text { month } 1-2 \text { months } \\
3-4 \text { months } \\
5-6 \text { months } \\
6 \text { months or more }\end{array}$ & $\begin{array}{l}3.9(29) \\
43.6(48) \\
16.4(18) \\
7.3(8) \\
6.4(7)\end{array}$ & $\begin{array}{l}13.8(103) \\
30.8(196) \\
28.7(183) \\
7.8(50) \\
16.5(105)\end{array}$ \\
\hline $\begin{array}{l}\text { Living arrangements* } \\
\text { At family home (of origin) } \\
\text { Renting } \\
\text { Own/mortgaged home } \\
\text { Other\# }\end{array}$ & $\begin{array}{l}47.7(51) \\
23.4(25) \\
28.0(30) \\
0.9(-)\end{array}$ & $\begin{array}{l}49.8(317) \\
31.4(200) \\
11.6(74 \\
7.1(45)\end{array}$ & $\begin{array}{l}\text { Missed significant life events due to } \\
\text { role/travel }\end{array}$ & $60.0(66)$ & $67.2(429)$ \\
\hline $\begin{array}{l}\text { Ever treated for a mental health or psychological } \\
\text { problem* }\end{array}$ & $33.6(37)$ & $20.4(130)$ & $\begin{array}{l}\text { Personal concern for safety while } \\
\text { travelling }\end{array}$ & $7.3(8)$ & $9.6(61)$ \\
\hline $\begin{array}{l}\text { Sought treatment for a mental health or psychological } \\
\text { problem in the past } 12 \text { months }\end{array}$ & $20.9(37)$ & $19.9(127)$ & & & \\
\hline
\end{tabular}

${ }^{* *} p<.001,{ }^{*} p<.01$

$\wedge$ Includes 'other', 'do not know' and 'do not want to say'

\#Includes living with a host family

$=0.2$ ), and there was a similar trend for the subscale for severe depression on the GHQ-28 (which includes items on suicidal ideation) but this was not significant at the more stringent significance level $(p=.022)$.

\section{Interaction Effects}

No significant $(p<.01)$ interaction effects were found between para-athlete status and gender for any included measures. There was a trend for an interaction for GHQ anxiety/insomnia, with male athletes from para-sports scoring higher on anxiety/insomnia than males from non-para-sports, and conversely females from non-parasports reporting higher anxiety/insomnia than females athletes from para-sports $(F(1,699)=5.64, p=.018)$.

\section{Discussion}

In this representative and national sample of elite athletes from para- and non-para-sports, minimal differences in mental health and wellbeing symptoms were observed between the athlete groups, with the exception of alcohol consumption and self-esteem, both being significantly lower in para-athletes. The few differences 
Table 2 Mental health symptoms among currently competing elite para-athletes and non-para-athletes

\begin{tabular}{|c|c|c|c|c|c|c|}
\hline \multirow[t]{2}{*}{ Variable } & \multirow[b]{2}{*}{ Total } & \multicolumn{2}{|c|}{$\begin{array}{l}\text { Para-athletes } \\
(n=110) \\
\text { Mean (SD) }\end{array}$} & \multirow[b]{2}{*}{ Total } & \multicolumn{2}{|c|}{$\begin{array}{l}\text { Non-para-athletes } \\
(n=639) \\
\text { Mean (SD) }\end{array}$} \\
\hline & & Males & Females & & Males & Females \\
\hline Psychological distress: $\mathrm{K}-10$ total score & $16.7(5.9)$ & $16.7(6.1)$ & $16.9(5.5)$ & $16.3(5.8)$ & $15.3(5.5)$ & $17.3(6.3)$ \\
\hline $\begin{array}{l}\text { General Health Questionnaire-28 (GHQ-28): total score } \\
\text { Anxiety/insomnia subscale score } \\
\text { Somatic symptoms subscale score } \\
\text { Social dysfunction subscale score } \\
\text { Severe depression subscale score }\end{array}$ & $\begin{array}{l}20.8(10.6) \\
5.6(4.3) \\
5.8(3.8) \\
7.4(2.3) \\
1.8(2.9)\end{array}$ & $\begin{array}{l}20.8(10.9) \\
5.8(4.5) \\
5.6(3.4) \\
7.3(2.1) \\
2.0(3.4)\end{array}$ & $\begin{array}{l}21.5(11.0) \\
5.6(4.4) \\
6.3(4.4) \\
7.6(2.8) \\
2.0(2.9)\end{array}$ & $\begin{array}{l}19.4(10.8) \\
5.4(4.5) \\
5.4(3.5) \\
7.1(2.6) \\
1.4(2.7)\end{array}$ & $\begin{array}{l}16.5(9.8) \\
4.1(4.2) \\
4.6(3.4) \\
6.7(2.5) \\
1.1(2.4)\end{array}$ & $\begin{array}{l}21.6(11.4) \\
6.4(4.7) \\
6.1(3.6) \\
7.4(2.8) \\
1.7(3.0)\end{array}$ \\
\hline $\begin{array}{l}\text { Satisfaction with life scale: total score } \\
\text { Mental wellbeing total score }\end{array}$ & $\begin{array}{l}25.5(3.8) \\
48.9(8.1)\end{array}$ & $\begin{array}{l}25.6(5.8) \\
49.2(7.6)\end{array}$ & $\begin{array}{l}25.3(6.0) \\
49.1(8.9)\end{array}$ & $\begin{array}{l}26.7(5.9) \\
50.1(9.4)\end{array}$ & $\begin{array}{l}27.3(5.9) \\
52.4(8.8)\end{array}$ & $\begin{array}{l}26.5(6.0) \\
48.6(9.4)\end{array}$ \\
\hline Self-esteem total score & $20.7(4.8)$ & $21.1(4.8)$ & $20.3(5.4)$ & $21.6(4.7)^{*}$ & $22.7(4.5)$ & $20.9(4.8)$ \\
\hline $\begin{array}{l}\text { Male depression rating scale total score } \\
\text { Anger and aggression subscale score } \\
\text { Risk-taking subscale score } \\
\text { AUDIT Total score }\end{array}$ & $\begin{array}{l}5.1(6.9) \\
2.7(4.2) \\
2.4(3.6) \\
2.7(3.1)\end{array}$ & $\begin{array}{l}5.9(7.3) \\
3.2(4.5) \\
2.6(3.8) \\
3.6(3.5)\end{array}$ & $\begin{array}{l}4.5(6.7) \\
2.4(4.2) \\
2.1(3.2) \\
1.8(2.2)\end{array}$ & $\begin{array}{l}6.1(7.2) \\
3.2(4.5) \\
2.9(3.5) \\
\mathbf{4 . 2}(\mathbf{4 . 0})^{* *}\end{array}$ & $\begin{array}{l}6.1(7.0) \\
3.1(4.2) \\
2.9(3.5) \\
4.9(3.5)\end{array}$ & $\begin{array}{l}6.6(7.7) \\
3.6(4.9) \\
3.0(3.7) \\
3.8(3.8)\end{array}$ \\
\hline Alcohol consumption subscale score & $3.9(1.5)$ & $3.4(1.8)$ & $2.0(1.3)$ & $4.3(1.8) * *$ & $4.3(2.3)$ & $3.3(1.7)$ \\
\hline Alcohol dependence subscale score & $0.4(0.7)$ & $0.5(0.7)$ & $0.3(0.7)$ & $0.5(1.0)$ & $0.5(1.1)$ & $0.4(1.0)$ \\
\hline \multirow[t]{2}{*}{ Alcohol-related problem subscale score } & $1.7(1.6)$ & $1.8(1.7)$ & $1.1(0.9)$ & $1.3(1.9)$ & $1.3(1.8)$ & $1.3(2.1)$ \\
\hline & $\%$ & $\%$ & $\%$ & $\%$ & $\%$ & $\%$ \\
\hline Quality of life: 'good' and 'very good' categories & 79.3 & 84.6 & 71.1 & 81.0 & 85.5 & 77.7 \\
\hline GHQ-28: scoring at or above 'caseness' threshold & 37.7 & 37.3 & 38.6 & 34.5 & 24.7 & 40.1 \\
\hline EDE-Q 'high' body weight dissatisfaction & 25.3 & 17.6 & 34.2 & 25.8 & 16.3 & 33.3 \\
\hline EDE-Q 'high' body weight and shape dissatisfaction & 26.7 & 21.6 & 44.8 & 26.2 & 23.1 & 39.7 \\
\hline Problem Gambling Severity Index: non-problem gambling category & 66.7 & 60.0 & 83.3 & 67.5 & 58.1 & 89.2 \\
\hline Hazardous alcohol consumption threshold (AUDIT) & 13.0 & 21.2 & 2.6 & 15.7 & 20.6 & 12.2 \\
\hline
\end{tabular}

${ }^{* *} p<0.001,{ }^{*} p<0.01$ for adjusted models

observed between the athlete groups is somewhat inconsistent with literature from the general population, where it has been suggested that the rates of mental illhealth, specifically depression, among the general population of people with disabilities are higher than in individuals without an impairment [12, 32-36]. It may be that a range of strengths-based cognitive, behavioural, and affective characteristics and qualities previously identified in para-athletes, including increased social integration, positive social-support networks, autonomy, and independence gained through sport [6,7], are related to the current findings. Overall, our results counter what has been deemed a problematic and discriminatory assumption, that disability is inevitably associated with mental health symptoms or disorders [37, 38].

\section{Mental Health and Wellbeing Symptoms in Para-athletes}

Para-athletes reported significantly lower alcohol consumption than non-para counterparts, which is consistent with the pattern observed in non-athletic populations, where lower rates of alcohol use and misuse are found among people with learning disabilities compared to nondisabled peers (see [39] for a review). Less is known about the prevalence and potential aetiologies for alcohol use in other forms of impairment in the general population, and given the paucity of literature on alcohol use among paraathletes, it is difficult to draw conclusions as to the context for the current results. In the current cohort, the differences in alcohol use were explained by greater alcohol consumption among non-para-athletes, rather than differences in alcohol dependence or alcohol-related problems (e.g. personal feelings of guilt/remorse, alcohol-related injury to self/others), which were low among both groups.

The results also demonstrated that para-athletes report comparatively lower levels of self-esteem. This finding is consistent with earlier work that reported significantly higher levels of global self-esteem in Flemish Olympic athletes than Paralympic athletes [40]; although this smaller study consisted of few female athletes $(n=3)$, none of whom were Paralympians. A possible explanation for this difference may relate to a number of impairment-related factors that may also affect global self-esteem, including being 'misclassified' or assigned to the wrong impairment category for competition [41], or negative coaching behaviours $[5,42]$, which is an avenue for exploration in future research.

Our results also indicated that para-athletes reported higher scores on the GHQ-28 subscale for severe 
depression, which include four items related to suicidal ideation, than non-para-athletes. Despite not being statistically significant given our stringent alpha, this result requires further research attention, particularly in light of the observation that 1 in 3 para-athletes (37\%) in the current sample met the threshold for probable caseness on the GHQ-28, indicating symptoms at a level that would usually warrant a need for professional healthcare. Repeat studies in subsequent samples of para-athletes are required to determine if this finding is replicated, particularly given prior evidence to indicate a greater tendency for depressive symptomology among paraathletes $[9,43]$ and those with an impairment in the general population [12, 32-35].

A number of significant differences were observed between para- and non-para-athletes on a range of correlates, which may have served as protective factors to mental health symptoms among athletes from parasports. On average, athletes from para-sports were significantly older (31 years vs 23 years; higher age has been shown to be a protective factor for mental health morbidity [44]); spent more time as an NSO categorised athlete, which may represent greater career longevity and stability in terms of support provided from their sport; reported less travel, minimising their time away from home and their usual social supports; and were more likely to have received treatment for a mental health problem, which may be reflective of help-seeking behaviour. Greater matching of para- and non-parasamples in future research will be important to understand whether the pattern of results reported here is replicated. The proportion of athletes from para-sports in paid employment in the current sample (59.2\%) is higher than that reported in individuals with an impairment in the general population (48\%) [36] and para-athletes participated in significantly more voluntary unpaid work than non-para-athletes. Athletes from para-sports have described the positive emotions experienced when 'giving back' to the community, through helping change people's perceptions about impairments and being role models for other people with impairments [6]. These experiences have in turn been described by para-athletes as benefiting their sense of social integration, feelings of self-acceptance and providing a sense of purpose outside sport [6].

\section{Clinical Implications}

Our findings highlight a similar need for mental health supports across athlete populations. Understanding the prevalence and possible risk and prognostic factors of mental health symptoms specific to athlete subpopulations can greatly assist in mental health assessment, formulation and the selection and development of appropriate prevention and clinical interventions that may be most efficacious with each subgroup.

\section{Strengths and Limitations}

The response rate for para-athletes (44\%), while acceptable given the survey methodology (and consistent with or better than other surveys), limits confidence in the representativeness of the sample. The cross-sectional design also limits the ability to draw stronger conclusions regarding the contribution of correlates of observed differences in mental health outcomes between para- and non-para-athletes and whether the few observed differences between the groups are sustained over time. This study also relied on self-report, which may have introduced bias in terms of social desirability. The anonymous nature of the survey likely negated this issue to a degree, facilitating reliability in responses. The large sample is a strength, along with the use of a wide range of mental health measures and a range of correlates. This allowed for the adjustment of potentially confounding variables and the examination of a greater range of mental health constructs than has previously been reported in the literature on elite athletes. A further limitation was the inability to adapt the survey for visually impaired athletes, something that should be considered in future studies and that we were unable to collect information on impairment among para-athletes.

\section{Conclusions}

Differences between mental health factors among athletes from para-sports and non-para-sports appear to be minimal in this large sample of Australian elite athletes. Para-athletes reported lower alcohol consumption but also lower self-esteem compared to their counterparts from non-para-sports. These findings provide new knowledge that can inform evidence-based approaches to addressing mental health problems in para- and nonpara-athletes. There is an urgent need to continue to extend this work, so that efforts to improve mental health prevention, early intervention and clinical care are meeting the distinct needs of different athlete populations and this should be a target for future research.

\section{Abbreviations \\ AIS: Australian Institute of Sport; NSO: National Sporting Organisation; GHQ- 28: General Health Questionnaire; K-10: Kessler 10; WEMWBS: Warwick- Edinburgh Mental Wellbeing Scale; PGSI: Problem Gambling Severity Index; MDRS: Male Depression Risk Scale; AUDIT: Alcohol Use Disorders Test; EDEQ: Eating Disorders Examination Questionnaire}

\section{Acknowledgements}

We thank Mr. Daniel Josifovski for his assistance with the survey logistics and Ms. Emily Mawson for assistance with data analysis. We also thank Dr. Lyndel Abbott from Paralympics Australia for her assistance with the data interpretation. 


\section{Authors' Contributions}

LO, RP and SR conceived the idea for the study. RP and SR were responsible for the survey design and survey implementation. $L O$ and RP conducted the analyses. $\mathrm{LO}$ drafted the initial manuscript. $\mathrm{MB}$ and $\mathrm{MC}$ contributed to the survey design. All authors contributed to the data interpretation and revision of the final manuscript. The authors read and approved the final manuscript.

\section{Authors' Information}

All authors are practising mental health clinician-researchers in clinical psychology or social work from leading organisations in sport (Australian Institute of Sport) and youth mental health (Orygen's Elite Sport and Mental Health Program, co-affiliated with the Centre for Youth Mental Health, The University of Melbourne). The authors draw on our expertise, as well as international experience in global mental health initiatives, including a mental health partnership with the World Economic Forum (Orygen, 2019), as coauthors of the International Olympic Committee's Expert Consensus Statement on Elite Athlete Mental Health (Reardon et al. 2019) and as leading members of the AIS Athlete Wellbeing and Engagement programme who founded the AIS Mental Health Referral Network.

\section{Funding}

This study was funded by the Australian Sports Commission.

\section{Availability of Data and Materials}

The datasets generated and/or analysed during the current study are not publicly available as ethics has not approved the sharing of data in this manner.

\section{Declarations}

\section{Ethics Approval and Consent to Participate}

All participants were provided with information about the purpose of the survey prior to commencing and informed consent was implied by athletes choosing to click to commence the survey. The University of Melbourne Human Ethics Research Committee approved the study (\#1442705).

\section{Consent for Publication}

Not applicable

\section{Competing Interests}

Authors MB and MC are employed by the Australian Institute of Sport, which is funded by Sport Australia. Their involvement in the study included the survey design, data interpretation and contributions to the final draft manuscript, but not to the survey implementation or data analysis.

\section{Author details}

'Orygen, 35 Poplar Road, Parkville, Melbourne, Victoria 3052, Australia ${ }^{2}$ Centre for Social and Early Emotional Development, School of Psychology, Deakin University, Geelong, Australia. ${ }^{3}$ IMPACT Institute for Mental and Physical Health and Clinical Translation, Deakin University, Geelong, Australia. ${ }^{4}$ The Centre for Youth Mental Health, University of Melbourne, Melbourne, Australia. ${ }^{5}$ Australian Institute of Sport, Athlete Wellbeing and Engagement, Canberra, Australia.

Received: 2 August 2020 Accepted: 2 August 2021

Published online: 24 August 2021

\section{References}

1. Reardon CL, Hainline B, Aron CM, Baron D, Baum AL, Bindra A, et al. Mental health in elite athletes: International Olympic Committee consensus statement (2019). Br J Sports Med. 2019;53(11):667-99. https://doi.org/10.113 6/bjsports-2019-100715.

2. Gouttebarge V, Castaldelli-Maia JM, Gorczynski P, Hainline B, Hitchcock ME, Kerkhoffs GM, et al. Occurrence of mental health symptoms and disorders in current and former elite athletes: a systematic review and meta-analysis. Br J Sports Med. 2019;53(11):700-6. https://doi.org/10.1136/bjsports-2019-1 00671.

3. Rice SM, Purcell R, De Silva S, Mawren D, McGorry PD, Parker AG. The mental health of elite athletes: a narrative systematic review. Sports Med. 2016;46(9):1333-53. https://doi.org/10.1007/s40279-016-0492-2.
4. Bundon A, Hurd CL. Honey or vinegar? Athletes with disabilities discuss strategies for advocacy within the Paralympic Movement. J Sport Soc Issues. 2015;39(5):351-70. https://doi.org/10.1177/0193723514557823.

5. Arnold R, Wagstaff CRD, Steadman L, Pratt $Y$. The organisational stressors encountered by athletes with a disability. J Sports Sci. 2017;35(2):1187-96. https://doi.org/10.1080/02640414.2016.1214285.

6. Macdougall $\mathrm{H}, \mathrm{O}$ 'Halloran $\mathrm{P}$, Sherry E, Shields N. Needs and strengths of Australian para-athletes: Identifying their subjective psychological, social, and physical health and well-being. The Sport Psychologist. 2016;30(1):1-12. https://doi.org/10.1123/tsp.2015-0006.

7. Powell AJ, Myers TD. Developing mental toughness: lessons from paralympians. Front Psychol. 2017;8:1270.

8. Macdougall $\mathrm{H}, \mathrm{O}^{\prime}$ Halloran P, Shields N, Sherry E. Comparing the well-being of para and olympic sport athletes: a systematic review. Adapt Phys Act Q. 2015;32(3):256-76

9. Horvat M, Roswal G, Jacobs D, Gaunt S. Selected psychological comparisons of able-bodied and disabled athletes. Phys Educ. 1989:46(4):202.

10. Wiśniowska M, Tasiemski T, Bauerfeind J. Athletic identity assessment in disabled sitting volleyball players. Physiotherapy. 2012;20(1):10-9.

11. Swartz L, Hunt X, Bantjes J, Hainline B, Reardon CL. Mental health symptoms and disorders in Paralympic athletes: a narrative review. Br J Sports Med. 2019;53(12):737-40. https://doi.org/10.1136/bjsports-2019-100731.

12. Watson N, Roulstone A, Thomas C. Routledge handbook of disability studies. London, New York: Routledge; 2014.

13. Purcell R, Rice S, Butterworth M, Clements M. Rates and correlates of mental health symptoms in currently competing elite athletes from the Australian National High-Performance Sports System. Auckland, NZ: Sports medicine; 2020.

14. Goldberg D, Hillier VF. A scaled version of the general health questionnaire. Psychol Med. 1979;9(1):139-45. https://doi.org/10.1017/S0033291700021644.

15. Goldberg DP, Gater R, Sartorius N, Ustun TB, Piccinelli M, Gureje O, et al. The validity of two versions of the GHQ in the WHO study of mental illness in general health care. Psychol Med. 1997;27(1):191-7. https://doi.org/10.1017/ S0033291796004242

16. Kessler RC, Andrews G, Colpe LJ, Hiripi E, Mroczek DK, Normand SL, et al. Short screening scales to monitor population prevalences and trends in non-specific psychological distress. Psychol Med. 2002;32(6):959-6. https:// doi.org/10.1017/S0033291702006074.

17. Donker T, Comijs H, Cuijpers P, Terluin B, Nolen W, Zitman F, et al. The validity of the Dutch $\mathrm{K} 10$ and extended K10 screening scales for depressive and anxiety disorders. Psychiatry Res. 2010 Mar 30;176(1):45-50. https://doi. org/10.1016/j.psychres.2009.01.012.

18. Cornelius BL, Groothoff JW, van der Klink JJ, Brouwer S. The performance of the $\mathrm{K} 10, \mathrm{~K} 6$ and GHQ-12 to screen for present state DSM-IV disorders among disability claimants. BMC Public Health. 2013 Feb 12;13(1):128. https://doi.org/10.1186/1471-2458-13-128.

19. Bougie E, Arim RG, Kohen DE, Findlay LC. Validation of the 10-item Kessler psychological distress scale (K10) in the 2012 Aboriginal Peoples Survey. Health Rep. 2016:27(1):3-10.

20. Rosenberg M. Society and the adolescent self-image. Princeton, NJ: Princeton University Press; 1965. https://doi.org/10.1515/9781400876136.

21. Stewart-Brown S, Janmohamed K. Warwick-Edinburgh Mental Well-being Scale (WEMWBS). User Guide Version, 1. Scotland: The NHS Health Scotland, University of Warwick and University of Edinburgh; 2008.

22. Stewart-Brown S, Tennant A, Tennant R, Platt S, Parkinson J, Weich S. Internal construct validity of the Warwick-Edinburgh Mental Well-being Scale (WEMWBS): a Rasch analysis using data from the Scottish Health Education Population Survey. Health Qual Life Outcomes. 2009 Feb 19;7(1): 15. https://doi.org/10.1186/1477-7525-7-15.

23. Ferris J, Wynne $\mathrm{H}$. The Canadian problem gambling index: final report. Canadian Consortium for Gambling Research; 2001.

24. Rice S. Depression in Men: Development of the Male Depression Risk Scale (Doctoral dissertation) Australian Catholic University; 2011.

25. Fairburn CG, Cooper Z, O'Connor ME. Eating disorder examination. In: Fairburn CG, editor. Cognitive Behavior Therapy and Eating Disorders. New York: Guilford Press; 2008. p. 265-308.

26. Saunders JB, Aasland OG, Babor TF, De La Fuente JR, Grant M. Development of the Alcohol Use Disorders Identification Test (AUDIT): WHO Collaborative Project on Early Detection of Persons with Harmful Alcohol Consumption-II. Addiction. 1993:88(6):791-804. https://doi.org/10.1111/j.1360-0443.1993.tb02 093.x. 
27. Diener E, Emmons RA, Larsen RJ, Griffin S. The satisfaction with life scale. J Pers Assess. 1985;49(1):71-5.

28. Tennant C. Life events and psychological morbidity: the evidence from prospective studies. Psychol Med. 1983;13(3):483-6. https://doi.org/10.1017/ S0033291700047917.

29. Purcell R, Pathé M, Baksheev GN, MacKinnon A, Mullen PE. What mediates psychopathology in stalking victims? The role of individual-vulnerability and stalking-related factors. J Forensic Psychiatry Psychol. 2012;23(3):361-70. https://doi.org/10.1080/14789949.2012.679007.

30. Wilson CJ, Deane FP, Ciarrochi JV, Rickwood D. Measuring help seeking intentions: properties of the general help seeking questionnaire. Can J Couns. 2005;39:15-28.

31. Billings $A G$, Moos RH. The role of coping responses and social resources in attenuating the stress of life events. J Behav Med. 1981;4(2):139-57. https:// doi.org/10.1007/BF00844267.

32. Watson $\mathrm{N}$, Thomas C, Roulstone A. The changing terrain of disability studies. In: Watson N, Roulstone A, Thomas C, editors. Routledge Handbook of disability studies. New York: Routledge; 2012. p. 3-11.

33. Cooper SA, Smiley E, Morrison J, Williamson A, Allan L. Mental ill-health in adults with intellectual disabilities: prevalence and associated factors. The British journal of psychiatry : the journal of mental science. 2007 Jan;190(1): 27-35. https://doi.org/10.1192/bjp.bp.106.022483.

34. Kemp BJ, Krause JS. Depression and life satisfaction among people ageing with post-polio and spinal cord injury. Disabil Rehabil. 1999 May-Jun;21(5-6): 241-9. https://doi.org/10.1080/096382899297666.

35. Borthwick-Duffy SA. Epidemiology and prevalence of psychopathology in people with mental retardation. J Consult Clin Psychol. 1994;62(1):17-27. https://doi.org/10.1037/0022-006X.62.1.17.

36. Australian Institute of Health and Welfare (AlHW). Australia's welfare 2017. Australia's welfare series no. 13. AUS 214. 2017. Available from: https:// www.aihw.gov.au/reports/australias-welfare/australias-welfare-2017/ contents/table-of-contents

37. Watermeyer B. Claiming loss in disability. Disability \& Society. 2009;24(1):91102.

38. Watermeyer B, Görgens T. Disability and internalized oppression. In: EJR D, editor. Internalized oppression: the psychology of marginalized groups: Springer; 2014. p. 253-80.

39. Taggart L, Huxley A, Baker G. Alcohol and illicit drug misuse in people with learning disabilities: implications for research and service development. Adv Ment Health Learn Disabil. 2008;2(1):11-21. https://doi.org/10.1108/175301 80200800003

40. Van de Vliet P, Van Biesen D, Vanlandewijck C. Y. Athletic identity and selfesteem in Flemish athletes with a disability. European Journal of Adapted Physical Activity. 2008;1 (1):9-21. https://doi.org/10.5507/euj.2008.001.

41. Campbell E, Jones $\mathrm{G}$. Sources of stress experienced by elite male wheelchair basketball players. Adapt Phys Act Q. 2002;19(1):82-99.

42. Martin JJ. A personal development model of sport psychology for athletes with disabilities. J Appl Sport Psychol. 1999;2:181-93.

43. Wisniowska M, Tasiemski T, Bauerfeind J. Athletic identity assessment in disabled sitting volleyball players. Fizjoterapia. 2012;20:10-9.

44. McDowell MJ, Hughto JMW, Reisner SL. Risk and protective factors for mental health morbidity in a community sample of female-to-male transmasculine adults. BMC psychiatry. 2019;19(1):16. https://doi.org/10.1186/s12 888-018-2008-0.

\section{Publisher's Note}

Springer Nature remains neutral with regard to jurisdictional claims in published maps and institutional affiliations.

\section{Submit your manuscript to a SpringerOpen ${ }^{\circ}$ journal and benefit from:}

- Convenient online submission

- Rigorous peer review

- Open access: articles freely available online

- High visibility within the field

- Retaining the copyright to your article

Submit your next manuscript at $\boldsymbol{\nabla}$ springeropen.com 